\title{
No clear association emerges between intergenerational relationships and COVID-19 fatality rates from macro-level analyses
}

\author{
Bruno Arpino ${ }^{a, 1} \mathbb{D}$, Valeria Bordone ${ }^{b}$, and Marta Pasqualinic ${ }^{\mathrm{C}}$

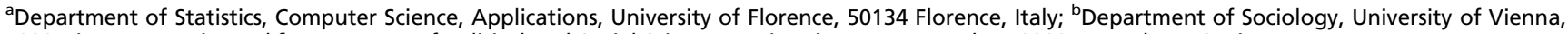 \\ 1090 Vienna, Austria; and 'Department of Political and Social Sciences, Universitat Pompeu Fabra, 08005 Barcelona, Spain
}

Edited by Douglas S. Massey, Princeton University, Princeton, NJ, and approved July 9, 2020 (received for review May 7, 2020)

\begin{abstract}
The severe acute respiratory syndrome coronavirus 2 originated in Wuhan, China at the end of 2019 and rapidly spread in more than 100 countries. Researchers in different fields have been working on finding explanations for the unequal impact of the virus and deaths from the associated coronavirus disease 2019 (COVID-19) across geographical areas. Demographers and other social scientists have hinted at the importance of demographic factors, such as age structure and intergenerational relationships. Our aim is to reflect on the possible link between intergenerational relationships and spread and lethality of COVID-19 in a critical way. We show that with available aggregate data it is not possible to draw robust evidence to support these links. In fact, despite a higher prevalence of intergenerational coresidence and contacts that is broadly positively associated with COVID-19 case fatality rates at the country level, the opposite is generally true at the subnational level. While this inconsistent evidence demonstrates neither the existence nor the absence of a causal link between intergenerational relationships and the severity of COVID-19, we warn against simplistic interpretations of the available data, which suffer from many shortcomings. We conclude by arguing that intergenerational relationships are not only about physical contacts between family members. Theoretically, different forms of intergenerational relationships may have causal effects of opposite sign on the diffusion of COVID-19. Policies should also take into account that intergenerational ties are a source of instrumental and emotional support, which may favor compliance to the lockdown and "phase-2" restrictions and may buffer their negative consequences on mental health.
\end{abstract}

intergenerational contacts | coresidence | coronavirus | COVID-19 | intergenerational relationships

$\mathbf{T}$ he rapid spread of the severe acute respiratory syndrome coronavirus 2 (SARS-CoV-2) made the need to understand which factors contribute to the diffusion of the virus urgent. The disease associated with the virus, coronavirus disease 2019 (COVID-19), is particularly deadly for older people (1), and it has been argued that the high prevalence of infected older people is crucial to understanding the high case fatality rate (CFR) observed in some countries, such as Italy $(2,3)$. Researchers have also hinted at intergenerational relationships (IR) as a driver of COVID-19 cases, especially among older people (4). In particular, it was argued that "intergenerational interactions, co-residence, and commuting may have accelerated the outbreak in Italy through social networks that increased the proximity of elderly to initial cases" (2).

The goal of this paper is to reflect on the suggested link between IR and the spread and lethality of COVID-19. We show that with available aggregate data it is not possible to draw robust evidence to support such a link. While we cannot demonstrate whether there is a (causal) link between IR and spread and lethality of COVID-19, our analyses at the subnational level warn against simplistic interpretations of country-level associations. We also discuss possible theoretical links between IR and the spread and lethality of COVID-19 that may work in opposite directions.

\section{Physical Intergenerational Relationships and the Spread and Lethality of COVID-19}

In line with simulation models of the spread of infectious diseases $(5,6)$, physical contact is the main transmission mode of the SARS-CoV-2 virus $(7,8)$, implying a positive link between physical contacts and infection rates. By physical contacts we refer to face-to-face meetings between at least two persons, be these relatives, friends, colleagues, or any other people.

Contact frequency between family members is known to be rather stable over the life course and constitutes a large part of individuals' overall contacts $(9,10)$, especially in some countries where contacts between grandparents and their grandchildren and between parents and their children are considerably more frequent than in others $(11,12)$. Italy and Spain, two of the European countries among the first to be seriously hit by the COVID-19 pandemic outside Asia, are also among the countries that display high prevalence of intergenerational coresidence (13-16) and of frequent intergenerational contacts between older parents and their adult children (17-19) and their grandchildren, also due to intensive grandparental childcare $(20,21)$. This may suggest a sort of "intergenerational contacts hypothesis," assuming that in countries where intergenerational face-to-face contacts between family members are more frequent higher infection rates are observed.

This hypothesis has been recently put forward $(2,22,23)$, arguing that the comparatively higher prevalence of intergenerational coresidence and/or contacts in some countries implies a

\section{Significance}

Several factors have been examined that contribute to the unequal impact of coronavirus disease 2019 (COVID-19) in terms of lethality and prevalence of cases across different geographical areas. Among them, intergenerational relationships (e.g., coresidence and contacts between family members of different generations) have been suspected to play a role in the spread and lethality of COVID-19. Our results show that available evidence on the link between intergenerational relationships and COVID-19 is inconclusive. Future studies need to use individuallevel data to obtain more robust statistical evidence on this link before any policy suggestion can be provided.

Author contributions: B.A. and V.B. designed research; M.P. performed research; and B.A., V.B., and M.P. wrote the paper.

The authors declare no competing interest.

This article is a PNAS Direct Submission.

Published under the PNAS license.

${ }^{1}$ To whom correspondence may be addressed. Email: bruno.arpino@unifi.it.

This article contains supporting information online at https://www.pnas.org/lookup/suppl/ doi:10.1073/pnas.2008581117/-/DCSupplemental.

First published July 22, 2020. 
higher vulnerability to the epidemic that disproportionately affects older adults. However, only one study (4) provides direct evidence in support of the "intergenerational contacts hypothesis." Using data from 24 countries (Australia plus some European and East-Asian countries), the authors found a positive correlation at the country level between the percentage of adults aged 30 to 49 y living with their parents and CFR (4). The authors argue that this finding highlights the role of IR in spreading COVID-19 to older people. These findings have been criticized in another study (24), where it was noted that if one compares different Italian regions an opposite result would be obtained. We extend the analyses in these contributions by considering a larger set of IR indicators at both country and subnational levels and from two different datasets. We also add a brief theoretical discussion on the role of nonphysical IRs in respect to the spread and lethality of COVID-19.

\section{Results}

We perform very simple statistical analyses to examine associations between IR and COVID-19 CFR (Methods). Our analyses are organized in three steps. First, using data from the Survey of Health, Aging and Retirement in Europe (SHARE) we examine country-level associations between several IR measures and CFR (for 19 countries). Second, we account for the within-country variability in both IR and COVID-19 fatality rates and examine correlations at the NUTS-2 level.* These analyses are restricted to the eight countries for which we have subnational information on COVID-19 deaths and cases. For Germany, COVID-19 information is available at the NUTS-1 level instead of NUTS-2. Finally, we zoom in on Italy and reexamine the associations at the NUTS- 2 level using data from the nationally representative Family and Social Subjects (FSS) survey. We examine Italian data in more detail because, as discussed in the Introduction, there is a vast literature on the comparatively higher prevalence of intergenerational coresidence and frequent contacts in this country. Italy has also been among the first non-Asian countries to be severely hit by the COVID-19 pandemic. Finally, the spread of COVID-19 cases in Italy has been taken as an illustrative case for the "intergenerational contacts hypothesis" by previous studies (2).

Between-Country Associations (19 European Countries). Table 1 reports IR indicators measured at the country level, sorted in descending order of CFR. From this table a clear pattern of association at the country level does not emerge. In fact, in several cases, countries in the highest tertiles of CFR fall in the lowest tertiles of IR indicators, and vice versa. For example, France and Belgium exhibit the highest CFR values and belong to the lowest tertile of values for intergenerational coresidence $(\leq 16.3 \%)$.

The lack of a clear pattern of association at the country level is confirmed by the Spearman's correlation coefficients (S) between CFR and each IR indicator (Table 2, rows 1 and 2). Most Spearman coefficients are positive, denoting that in countries with "stronger" IR a higher lethality of COVID-19 is generally found. Results are, however, not consistent for all IR indicators, as is the case of coresidence $(\mathrm{S}=-0.11)$. Restricting the sample to the eight countries for which data at the regional level are available further highlights mixed findings about the association between CFR and IR indicators: Negative associations are found for coresidence, geographic proximity, and intergenerational contacts, while a positive association holds for grandchild care provision indicators.

*NUTS stands for Nomenclature of Territorial Units for Statistics and is a geographica system, according to which the territory of the European Union is divided into hierarchical levels.
The generally small and not always consistent correlations in Table 2 suggest that conclusive interpretations cannot be derived based on country-level associations.

Within-Country Associations (Eight European Countries). We examined within-country associations between CFR (percent) and IR indicators for the eight countries for which we have subnational data. Spearman's correlation coefficients at the NUTS-2 level (NUTS-1 level for Germany) as reported in Table 2 display substantial differences across the considered countries. Correlations for living in multigenerational households range between -0.50 (Italy) and +0.39 (Switzerland). A negative association is also found for Sweden. The correlation at the regional level between CFR and geographic proximity is negative in Italy, Sweden, Spain, and Germany. Frequency of contacts also displays both negative (Italy and Sweden) and positive (France, Spain, Poland, Switzerland, and Germany) associations with CFR. Mixed correlations also result from the analysis of the provision of grandchild care indicators.

Within-Country Associations (Italy). Table 3 reports CFR and IR indicators measured for each region of Italy, sorted in descending order of COVID-19 fatality rate; IR indicators are calculated on the population aged $60+y$ to allow a comparison with findings drawn from SHARE data. In general, for most IR indicators, a negative pattern of association with CFR emerges. Associations between IR indicators and CFR are reported in Table 2 (last row). Findings clearly hint at negative associations between CFR and all of the considered IR indicators: intergenerational coresidence, geographic proximity, contact frequency, and grandparental childcare. Estimated correlations also tend to be high compared to those obtained by analyzing SHARE data at the country level.

As a robustness check we replicated the previous analyses using the number of COVID-19 cases per 100,000 persons calculated on the whole population or only on the $60+$ population and we obtained similar results (SI Appendix, Tables S1-S5).

\section{Conclusion and Discussion}

The aim of this paper was to critically discuss the role of IRs in the spread and lethality of COVID-19, providing empirical evidence to counterargue that a higher impact of the pandemic in some areas could be explained by more contact, geographical proximity, or functional solidarity (e.g., grandparental childcare) across generations within the family.

At the country level, associations between IR indicators and COVID-19 CFR are usually positive, though small. Instead, at the subnational level negative associations are often observed. We cannot conclude from this analysis that IR negatively impact the spread and lethality of COVID-19, but this evidence highlights the need for further investigations of the role of IR. Because of the inconsistent results we obtained at the country and subnational levels, we caution against overinterpretation of the empirical evidence on the association between IR and the spread and lethality of COVID-19.

There are two additional important aspects to consider that further suggest carefulness in this respect. First, when analyzing the effect of IR on spread and lethality of COVID-19, one should take, as usual, confounding factors into account. At the country level, a positive association may be spurious because intergenerational contacts are more frequent in "weaker" welfare states (25) where, for example, public health services tend to be less available and/or of lower quality. Similarly, at the regional level, a negative association between IR and COVID-19 cases may be due to the negative association between IR and the prevalence of older people in nursing and care homes, which has been found to have a crucial role in the diffusion of COVID-19 cases (26). An example of this pattern is the Lombardy region that is characterized by one of the highest CFR of COVID-19 in Italy and by a comparatively low prevalence 
Table 1. CFR of COVID-19 and IRs indicators for the population aged $60+y$, by country

\begin{tabular}{|c|c|c|c|c|c|c|}
\hline \multirow[b]{2}{*}{ Countries } & \multirow{2}{*}{$\begin{array}{l}\text { COVID-19 } \\
\text { CFR, \% }\end{array}$} & \multirow{2}{*}{$\frac{\text { Coresidence }}{\text { Multigenerational } \mathrm{HH}, \%}$} & \multirow{2}{*}{ 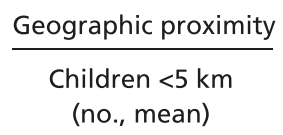 } & \multirow{2}{*}{$\begin{array}{c}\text { Intergenerational contacts } \\
\begin{array}{c}\text { Children close contacts } \\
\text { (d, mean) }\end{array}\end{array}$} & \multicolumn{2}{|c|}{ Grandchild care } \\
\hline & & & & & Grandchild care, \% & $\begin{array}{c}\text { Grandchild care } \\
\text { (d, mean) }\end{array}$ \\
\hline Belgium & 15.43 & 13.66 & 0.88 & 174.45 & 37.24 & 34.95 \\
\hline Italy & 13.58 & 40.91 & 1.21 & 298.40 & 23.20 & 40.12 \\
\hline Sweden & 12.01 & 5.66 & 0.59 & 118.33 & 36.02 & 13.12 \\
\hline The Netherlands & 11.81 & 8.38 & 0.97 & 172.71 & 38.29 & 21.58 \\
\hline Slovenia & 5.89 & 47.45 & 1.11 & 313.42 & 29.84 & 36.31 \\
\hline Ireland & 5.60 & 25.28 & 1.10 & 162.45 & 34.58 & 35.10 \\
\hline Greece & 5.36 & 42.41 & 1.10 & 279.85 & 26.29 & 39.34 \\
\hline Denmark & 4.94 & 5.67 & 0.60 & 113.02 & 42.13 & 15.14 \\
\hline Poland & 4.72 & 49.67 & 1.31 & 231.19 & 33.85 & 53.99 \\
\hline Switzerland & 4.64 & 16.27 & 0.72 & 129.81 & 24.48 & 17.84 \\
\hline Czech Republic & 2.99 & 25.28 & 0.97 & 209.02 & 30.86 & 28.52 \\
\hline Luxembourg & 2.35 & 16.19 & 0.71 & 184.33 & 27.77 & 28.14 \\
\hline
\end{tabular}

Source: Authors' elaborations on data from SHARE, waves 1, 2, 4, 5, and 6. Sampling weights have been applied in the construction of the IR indicators. Countries are displayed in descending order of CFR. The grayscale refers to the percentile distribution, with the lightest gray for the cases below $33 \%$ and the darkest for those above the $66 \%$. COVID-19 cases data were collected on the last available date at the time of finalizing the study (27 April 2020$)$. $\mathrm{HH}=$ households.

Column labels: COVID-19 = CFR of COVID-19\% (at the time of finalizing the study, 27 April 2020); coresidence $=$ prevalence of residents living in multigenerational household; geographical proximity = mean of number of children living $<5 \mathrm{~km}$; Intergenerational contacts = mean number of days in a year spent together with children living $<5 \mathrm{~km}$; grandchild care $=$ percent of respondents reporting grandchild care and mean number of grandchildren cared from the respondent. $\mathrm{HH}=$ households.

of intergenerational coresidence and contacts (Table 3), with at the same time a relatively high prevalence of older people living in care residences (27).
Other confounding factors may be represented by population density, level of commuting for job-related reasons, and social relationships other than IR which have also been proposed as

Table 2. Spearman's correlation coefficients between CFR of COVID-19 and intergenerational relations indicators at country and the regional levels (by country)

\begin{tabular}{|c|c|c|c|c|c|c|}
\hline \multirow[b]{2}{*}{ Level of analysis } & \multirow{2}{*}{$\frac{\text { No. of units }}{(1)}$} & \multirow{2}{*}{$\frac{\text { Coresidence }}{(2)}$} & \multirow{2}{*}{$\frac{\text { Geographic proximity }}{\text { (3) }}$} & \multirow{2}{*}{$\frac{\text { Intergenerational contacts }}{(4)}$} & \multicolumn{2}{|c|}{ Grandchild care } \\
\hline & & & & & (5) & (6) \\
\hline \multicolumn{7}{|l|}{ Country (SHARE) } \\
\hline 19 countries & 19 & -0.11 & 0.14 & 0.05 & 0.32 & 0.15 \\
\hline 8 countries & 8 & -0.14 & -0.16 & -0.19 & 0.42 & 0.14 \\
\hline \multicolumn{7}{|l|}{ Region (SHARE) } \\
\hline France & 17 & 0.16 & $0.52 *$ & 0.18 & 0.00 & 0.25 \\
\hline Italy & 19 & $-0.50 * *$ & -0.38 & $-0.43^{*}$ & -0.26 & -0.07 \\
\hline Sweden & 8 & -0.14 & -0.30 & -0.16 & -0.40 & 0.28 \\
\hline Spain & 18 & 0.03 & -0.20 & 0.11 & 0.13 & 0.26 \\
\hline Poland & 6 & 0.08 & 0.08 & 0.14 & 0.65 & 0.48 \\
\hline Switzerland & 7 & 0.39 & 0.60 & $0.71 *$ & 0.60 & $0.71 *$ \\
\hline Portugal & 6 & 0.31 & 0.54 & 0.31 & 0.65 & $0.94 * *$ \\
\hline Germany & 16 & 0.11 & -0.06 & 0.02 & $0.42 *$ & 0.19 \\
\hline Italy (FSS) & 21 & $-0.55^{* * *}$ & $-0.49 * *$ & $-0.48 * *$ & $-0.48 * *$ & $-0.48 * *$ \\
\hline
\end{tabular}

Source: Authors' elaborations on data from SHARE, waves 1, 2, 4, 5, and 6) and from FSS for Italy; individuals aged 60+ y. Sampling weights have been applied in the construction of the IR indicators. $* * * P<0.01, * * P<0.05, * P<0.1$. We report separately the estimated associations for the subsample of countries (8) for which we have regional data from SHARE.

Column labels: (1) Number of countries or regional units (NUTS-2; NUTS-1 for Germany); (2) multigenerational household; (3) children <5 km (number, mean) for SHARE and Parents close (percent) for FSS; (4) children living $<5 \mathrm{~km}$ with contacts (days, mean) for SHARE and Children contacts (mean, days) for FSS; (5) Grandchild care (percent); (6) grandchild care (days, mean). 
Table 3. CFR of COVID-19 and IRs indicators for the population aged $60+y$, by Italian regions

\begin{tabular}{|c|c|c|c|c|c|}
\hline \multirow[b]{2}{*}{ Italian regions } & \multirow{2}{*}{$\frac{\text { COVID-19 }}{\text { CFR, } \%}$} & \multirow{2}{*}{$\frac{\text { Coresidence }}{\text { Multigenerational } \mathrm{HH}, \%}$} & \multirow{2}{*}{$\frac{\text { Geographic proximity }}{\text { Children close (mean, no.) }}$} & \multirow{2}{*}{$\frac{\text { Intergenerational contacts }}{\text { Children contacts (mean, d) }}$} & \multirow[b]{2}{*}{ Grandchild care, $\%$} \\
\hline & & & & & \\
\hline Lombardy & 18.30 & 37.37 & 1.20 & 391.94 & 50.37 \\
\hline Marche & 14.42 & 43.25 & 1.20 & 436.64 & 52.85 \\
\hline Emilia-Romagna & 13.91 & 34.31 & 1.12 & 355.61 & 52.66 \\
\hline Aosta Valley & 11.97 & 32.51 & 1.04 & 352.08 & 42.80 \\
\hline Piedmont & 11.46 & 35.60 & 1.22 & 376.52 & 55.54 \\
\hline Abruzzo & 10.40 & 42.69 & 1.24 & 436.83 & 55.29 \\
\hline Apulia & 10.23 & 47.24 & 1.59 & 531.80 & 62.44 \\
\hline Trentino & 10.18 & 36.09 & 1.18 & 411.81 & 48.26 \\
\hline Friuli Venezia Giulia & 9.10 & 30.88 & 1.10 & 346.46 & 56.60 \\
\hline Tuscany & 8.66 & 39.32 & 1.22 & 388.76 & 57.06 \\
\hline Sardinia & 8.49 & 52.24 & 1.31 & 495.81 & 47.97 \\
\hline Basilicata & 6.83 & 44.36 & 1.42 & 509.86 & 57.13 \\
\hline Lazio & 6.21 & 42.77 & 1.21 & 421.56 & 51.67 \\
\hline Umbria & 4.74 & 43.18 & 1.32 & 452.56 & 60.77 \\
\hline
\end{tabular}

Source: Authors' elaborations on data from FSS. Sampling weights have been applied in the construction of the IR indicators. Regions are displayed in descending order of CFR. The grayscale refers to the percentile distribution with the lightest gray for the cases below $33 \%$ and the darkest for those above the $66 \%$.

Column labels: COVID-19 = CFR of COVID-19\% (at the time of finalizing the study, 27 April 2020); coresidence = prevalence of residents living in multigenerational household; geographic proximity $=$ mean of number of children living within $16 \mathrm{~km}$ from the respondent; intergenerational contacts $=$ mean number of days in a year spent together with children; grandchild care = prevalence of respondents reporting any grandchild care and mean number of grandchildren cared from the respondent. $\mathrm{HH}=$ households.

correlates of the prevalence of COVID-19 cases and/or lethality $(28,29)$. These confounding factors may operate in various ways, affecting the link between IR and COVID-19 CFR, thus making any claim from simple unadjusted associations doubtful. The association between IR and spread and lethality of COVID-19 should therefore be analyzed at a finer geographic level to allow accounting for confounding factors. Ideally, one should use individual data complemented with social network information to examine the likelihood of COVID-19 infection and death as a function of IR and other type of contacts. Unfortunately, these data are not currently available and specific (retrospective) data collection efforts should be implemented in this direction to provide solid empirical evidence on this issue.

Second, the "intergenerational contacts hypothesis" focuses on physical contacts and overlooks nonphysical forms of IR that may help in keeping the spread of the virus low. As emphasized by the multidimensional model of intergenerational solidarity $(30,31)$, IR may take different forms, not all involving physical contacts $(14,15,32)$. For example, geographical proximity determines the possibility of providing some forms of instrumental support (e.g., help with cooking or cleaning) but not others (like online shopping in today's digitalized world). Similarly, associational solidarity may include phone calls, also in digital form, that are cheaper and offer the possibility of video interactions, allowing a semblance of physical contact $(33,34)$.

If IR are not limited to physical contacts, the association between IR and the spread of COVID-19 is, from a theoretical perspective, even less clear-cut. A wide array of studies have shown that IR are important for individuals' health and wellbeing (e.g., refs. 35, 36). Applying the theoretical arguments that were used to explain this evidence to the spread of COVID-
19 one may even hypothesize a negative effect of IR. For example, the social control perspective (37) postulates that close family members are interested in keeping their kin in good health and to achieve this goal they exert pressure and control to inhibit family members' unhealthy behaviors and to promote their positive habits. Thus, for example, adult children may positively influence their older parents in complying with the measures taken by the government and/or local authorities to contrast the spread of COVID-19.

Along this line, social-behavioral models of IR posit that, satisfying social norms of family obligations, family members provide help and support to each other, thus complementing the role of the welfare state $(38-40)$. In the time of the COVID-19 pandemic, help provided by children (e.g., with [online] shopping) may aid older parents to stay at home and reduce their exposure to the virus. IR are also an important source of emotional support, which reduces the risk of depression and loneliness (41). This is another mechanism that may favor compliance with the "physical distancing" rule: People who receive more emotional support at home, even if at a distance (e.g., on the phone), may be less likely to go out to look for distractions and social contacts. As a side note, given the importance of nonphysical interactions among humans we also suggest, as others did (e.g., ref. 42), replacing the term "social distancing" with the term "physical distancing."

All in all, we have shown empirically that the association between IR and the COVID-19 CFR is not robust. We also argued that different forms of IR may have contraposing effects. Incorrect conclusions on the effect of IR on COVID-19 are not innocuous because policy implications based on evidence that is not solid may be ineffective and counterproductive. Help provided by family members may be particularly needed and useful 
in adverse situations to buffer their negative impact on mental health (43). Some studies already have documented increased mental health problems during the COVID-19 pandemic (e.g., ref. 44). Thus, IR may be especially needed to cope with the stress caused by the restrictions and the climate of uncertainty in the time of the COVID-19 pandemic. Policies that fight against the spread of COVID-19 and those oriented at the so-called phase 2 , that is, the postemergency phase, need to take into account the importance of instrumental and emotional support guaranteed by IR, which is particularly important in some countries and for older people.

\section{Methods}

Data. Data on IR were taken from two sources: SHARE (45) and the FSS (46) survey curried out by the Italian national statistical office. SHARE is a longitudinal survey on individuals aged $50+y$ in several European countries plus Israel. We considered individuals age $60+\mathrm{y}$ and excluded Israel in order to focus on European countries only; thus, the analyses were carried out on 19 countries (Austria, Belgium, Czech Republic, Denmark, Estonia, France, Germany, Greece, Hungary, Ireland, Italy, Luxembourg, The Netherlands, Poland, Portugal, Slovenia, Spain, Sweden, and Switzerland). To maximize the sample size at the NUTS-2 level we have pooled all regular waves $(1,2$, 4-6) and taken the first observation for each individual to avoid issues of selective attrition. We excluded waves 3 and 7 because they (mainly) collected retrospective information. Because the selected waves cover a long period of time (from 2004), we have replicated all of the analyses by using only the last three available waves (4-6) as a sensitivity check. Results generally confirm the main findings and suggest a stability of IR over time (SI Appendix, Tables S6-S9).

FSS is a repeated cross-sectional survey on the Italian population aged $18+y$. We have considered the last available wave (collected in 2016) which covers detailed information of about 24,753 individuals. These data allow obtaining estimates at NUTS-2 level (regions) with sufficient precision (sample size range 515 to 2,050 ). In order to make possible a comparison between the two sources of data, we selected the sample population aged $60+y$. However, all of the analyses on FSS have been also replicated on the entire sample as a further robustness check (the distribution of IR sorted in descending order of COVID-19 CFR and cases [per 100,000] are reported in SI Appendix, Tables S10 and S11; estimates of the Spearman correlation coefficients are reported in SI Appendix, Table S2).

CFR are calculated using cumulative number of COVID-19 cases and deaths $^{\dagger}$. The data were drawn from the "COVID-Open-Data" public repository, which daily collects data directly from each country's Ministry of Health (47). COVID-19 cases and deaths at the country level were collected on the last available date at the time of finalizing this work (27 April 2020). However, data at the subnational level were only available for some of the countries also included in SHARE. Thus, the within-country analyses could be implemented only for eight countries (France, Germany, Italy, Poland, Portugal, Spain, Sweden, and Switzerland). We also notice that while the FSS provides data for all of the Italian regions, the SHARE survey did not include cases for the Aosta Valley region.

Data on COVID-19 deaths and cases by country and age on 27 April were only available for 15 of the SHARE countries (Belgium, Spain, Ireland, Italy, Switzerland, The Netherlands, Sweden, Portugal, Austria, Germany, Denmark, Estonia, France, Czech Republic, and Greece). Data were drawn from the "COVerAGE-DB" online free data repository (48). Data for Portugal on 27 April were drawn from the country's specific epidemiological bulletin (49). Data on deaths due to COVID-19 on the 60+ population were not available for Estonia.

COVID-19 cases per 100,000 residents by age and region were also used for a replication of within-country analysis for Italy. Data were collected by the Italian Institute of Health (Istituto Superiore di Sanità) and are freely available online (50).

Variables. Information on family ties from SHARE and FSS data, aggregated at both country and regional levels, has been used to measure four specific aspects of IR: coresidence, geographic proximity, contact frequency, and provision of grandchild care. In the analyses of SHARE data, we focused on the sample aged $60+y$ old. We used the same restriction for the main

${ }^{\dagger}$ The COVID-19 CFR is defined as the ratio of deaths (D) associated with COVID-19 divided by the number of detected COVID-19 cases (N): CFR = D/N. In our analyses, the death and case counts are cumulative counts up to 27 April 2020. analyses based on FSS data. The rationale for considering the $60+y$ population rests on the fact that older people are the most vulnerable to the COVID-19 disease. Given the availability of FSS data for the population aged $18+y$, we also carried out a robustness check on the whole sample as the whole population is at risk of contracting the SARS-CoV-2 virus.

Intergenerational coresidence was assessed by calculating the prevalence of respondents (aged 18+y and/or 60+ y) living in multigenerational households (two or more generations).

Geographical proximity is measured differently in the SHARE and the FSS surveys. More specifically, we were able to use, alternatively, 5 and $25 \mathrm{~km}$ as thresholds for geographic proximity in the analyses based on SHARE data and $16 \mathrm{~km}$ for the FSS data. SHARE only provides information on geographical proximity to children. We calculated the percentage of individuals living close to at least one child and, for the FSS data only, also the percentage of individuals living close to at least one parent and the mean number of grandchildren living close to the respondent.

Frequency of contacts was also measured differently in the SHARE and FSS surveys. SHARE collects information on contact frequency of any type (physical and nonphysical) with each respondent's child. With FSS data we were able to measure physical contacts with parents and up to three children and grandchildren (those with whom the respondent has the most contacts). Given that in SHARE contacts also include nonphysical contact, in this case we calculated the percentage of individuals aged $60+y$ who have weekly or daily contacts with at least one child living close to them $(\leq 5 \mathrm{~km})$. To provide a measure of contacts that accounts also for the number of children the respondent has, we additionally measured the mean of the (equivalent) total number of daily contacts with all children in a year ${ }^{\ddagger}$. Similarly, with the FSS data we calculated the mean of the (equivalent) total number of days of contacts with parents, children, and grandchildren in a year, separately for the population $18+y$ and $60+y$.

Grandparental childcare is measured in SHARE by asking grandparents the frequency of care provided to their grandchildren, separately for each respondent's child. We estimated the percentage of individuals $60+y$ who provide any/daily/weekly care to at least one grandchild. Similar to what we did for contact frequency, we estimated the mean of the (equivalent) total number of days of grandchild care. The FSS data do not provide frequency of grandchild care. In this case, we estimated the mean number of grandchildren for whom care is provided, both for the $18+y$ and $60+y$ populations.

Each IR indicator was estimated using sampling weights both at the country and at the NUTS-2 level.

Statistical Analyses. Associations at the country and regional levels are both estimated using the nonparametric Spearman's rank correlation coefficient. The advantage of this indicator over the standard Pearson (linear) correlation coefficient is that it only takes the ranks of the two examined variables into account and so it is not sensitive to outliers, deviations from a linear relationship and measurement errors, which are likely to be particularly serious for the number of COVID-19 cases.

It is well known that data on COVID-19 cases are affected by several methodological issues (see, e.g., ref. 51), but they represent the best information available to date on infections covering many countries and regions. In any case, estimates from macrolevel analyses should be interpreted with caution.

Although all of the analyses reported in the manuscript refer to CFR, we have replicated them using COVID- 19 cases per 100,000 residents and COVID19 cases per 100,000 residents aged $60+y$ as robustness checks (findings are shown in SI Appendix, Tables S1-S5).

Data Availability. All data used in this manuscript are publicly available. COVID-19 data are available online $(48,49,52)$. SHARE data can be accessed upon registration at http://share-project.org/home0.html. FSS data can be accessed at https://www.istat.it/it/archivio/236637.

\footnotetext{
${ }^{\text {*}}$ The transformation of contacts frequency to the equivalent mean number of days in a year spent together has been done by replacing "every day" with 364 (7*52 wk); "some times per week" with $130(2 * 52 \mathrm{wk})$; "several times per week" with $208(4 * 52$ wk); "once a week" with 52; "less than $4 \mathrm{~d}$ a month" with 36 (3*12); "about every 2 wk" with $24(2 * 12)$; "about once a month" with 12; "some time in a year" with 5 ; less than once a month with 4 ; "never" with 0 . Then, we summed the estimated amount of time reported for each child.
} 
1. Z. Wu, J. M. McGoogan, Characteristics of and important lessons from the coronavirus disease 2019 (COVID-19) outbreak in China: Summary of a report of 72314 cases from the Chinese center for disease control and prevention. JAMA 323, 1239-1242 (2020).

2. J. B. Dowd et al., Demographic science aids in understanding the spread and fatality rates of COVID-19. Proc. Natl. Acad. Sci. U.S.A. 117, 9696-9698 (2020).

3. C. Dudel et al., Monitoring trends and differences in COVID-19 case fatality rates using decomposition methods: Contributions of age structure and age-specific fatality. https://osf.io/vdgwt/. Accessed 30 April 2020.

4. C. Bayer, M. Kuhn, (2020). "Intergenerational ties and case fatality rates: A crosscountry analysis" (IZA Discussion Paper 13114, IZA Institute of Labor Economics, Bonn, Germany, 2020).

5. T. C. Germann, K. Kadau, I. M. Longini Jr., C. A. Macken, Mitigation strategies for pandemic influenza in the United States. Proc. Natl. Acad. Sci. U.S.A. 103, 5935-5940 (2006).

6. J. Mossong et al., Social contacts and mixing patterns relevant to the spread of infectious diseases. PLoS Med. 5, e74 (2008).

7. C. Huang et al., Clinical features of patients infected with 2019 novel coronavirus in Wuhan, China. Lancet 395, 497-506 (2020).

8. N. C. Peeri et al., The SARS, MERS and novel coronavirus (COVID-19) epidemics, the newest and biggest global health threats: What lessons have we learned? Int J. Epidemiol., 10.1093/ije/dyaa033 (2020).

9. J. Sander, J. Schupp, D. Richter, Getting together: Social contact frequency across the life span. Dev. Psychol. 53, 1571-1588 (2017).

10. C. Wrzus, M. Hänel, J. Wagner, F. J. Neyer, Social network changes and life events across the life span: A meta-analysis. Psychol. Bull. 139, 53-80 (2013).

11. P. A. Dykstra, Cross-national differences in intergenerational family relations: The influence of public policy arrangements. Innov. Aging 2, igx032 (2018).

12. D. S. Reher, Family ties in Western Europe: Persistent contrast. Popul. Dev. Rev. 24 203-234 (1998)

13. M. Albertini, M. Kohli, The generational contract in the family: An analysis of transfer regimes in Europe. Eur. Sociol. Rev. 29, 828-840 (2013).

14. C. Tomassini, K. Glaser, D. A. Wolf, M. I. Broese van Groenou, E. Grundy, Living arrangements among older people: An overview of trends in Europe and the USA. Popul. Trends 115, 24-34 (2004).

15. K. Glaser et al., Trends in the prevalence of grandparents living with grandchild(ren) in selected European countries and the United States. Eur. J. Ageing 15, 237-250 (2018).

16. E. Grundy, M. Murphy, Coresidence with a child and happiness among older widows in Europe: Does gender of the child matter? Popul. Space Place 24, e2102 (2018)

17. V. Bordone, Contact and proximity of older people to their adult children: A comparison between Italy and Sweden. Popul. Space Place 15, 359-380 (2009).

18. K. Hank, Proximity and contacts between older parents and their children: A European comparison. J. Marriage Fam. 69, 157-173 (2007).

19. J. J. Yahirun, D. Hamplová, Children's union status and contact with mothers: A crossnational study. Demogr. Res. 30, 1413-1444 (2014).

20. V. Bordone, B. Arpino, A. Aassve, Patterns of grandparental childcare across Europe: The role of the policy context and working mothers' need. Ageing Soc. 37, 845-873 (2017)

21. D. Price, E. Ribe, G. Di Gessa, K. Glaser, "Grandparental childcare: A reconceptualisation of family policy regimes" in Grandparenting Practices Around the World, V. Timonen, Ed. (Policy Press, Bristol, UK, 2018), pp. 43-62.

22. A. Esteve, I. Permanyer, D. Boertien, La vulnerabilidad de las provincias españolas a la COVID-19 según su estructura por edad y de coresidencia: Implicaciones para el (des) confinamiento. Perspectives Demogràfiques 19, 1-4 (2020).

23. A. Esteve, I. Permanyer, D. Boertien, J. W. Vaupel, National age and co-residence patterns shape COVID-19 vulnerability. Proc. Natl. Acad. Sci. U.S.A. 117, 16118-16120 (2020).

24. M. Belloc, P. Buonanno, F. Drago, R. Galbiati, P. Pinotti, Cross-country correlation analysis for research on COVID-19. Vox-CEPR Policy Portal. https://voxeu.org/article/ cross-country-correlation-analysis-research-COVID-19. Accessed 26 April 2020.

25. H. Künemund, Intergenerational Relations Within the Family and the State, (Edward Elgar Publishing, Northampton, 2008), pp. 105-122.

26. A. Comas-Herrera, J. Zalakain, Mortality associated with COVID-19 outbreaks in care homes: early international evidence. International Long-Term Care Policy Network CPEC-LSE, 26 April 2020. https://ltccovid.org/2020/04/12/mortality-associated-withCOVID-19-outbreaks-in-care-homes-early-international-evidence/. Accessed 29 Apri 2020
27. L. Pelliccia, "Alcuni profili di assistenza nelle regioni" in L'assistenza agli anziani non autosufficienti in Italia ( $6^{\circ}$ Rapporto, Network Non Autosufficienza, Maggioli Editore, Rimini, 2017).

28. J. E. Harris, "The subways seeded the massive coronavirus epidemic in New York City" (NBER Working Paper W27021, National Bureau of Economic Research, Cambridge, $M A, 2020)$

29. R. Mogi, J. Spijker, The influence of social and economic ties to the spread of COVID19 in Europe. SocArXiv:10.31235/osf.io/sb8xn (13 April 2020)

30. V. L. Bengtson, "Intergenerational solidarity and the structure of adult child-parent relationships" in Families in Later Life: Connections and Transitions, A. J. Walker, M. Manoogian-O’Dell, L. McGraw, D. L. White, Eds. (Pine Forge Press, Thousand Oaks, CA, 2001), p. 53.

31. V. L. Bengtson, R. E. Roberts, Intergenerational solidarity in aging families: An example of formal theory construction. J. Marriage Fam. 53, 856-870 (1991)

32. P. A. Dykstra, T. Fokkema, Relationships between parents and their adult children: A West European typology of late-life families. Ageing Soc. 31, 545-569 (2011).

33. S. Peng et al., "Use of communication technology to maintain intergenerational contact: Toward an understanding of "digital solidarity" in Connecting Families? Communication Technologies, Generations, and the Life Course, B. B. Neves, C. Casimiro, Eds. (Polity, Bristol, 2018), pp. 159-180.

34. T. Quadrello et al., Grandparents use of new communication technologies in a European perspective. Eur. J. Ageing 2, 200-207 (2005).

35. B. Arpino, V. Bordone, Does grandparenting pay off? The effect of childcare on Grandparents' cognitive functioning. J. Marriage Fam. 76, 337-351 (2014)

36. P. A. Thoits, Mechanisms linking social ties and support to physical and mental health. J. Health Soc. Behav. 52, 145-161 (2011).

37. D. Umberson, T. Pudrovska, C. Reczek, Parenthood, childlessness, and well-being: A life course perspective. J. Marriage Fam. 72, 612-629 (2010).

38. T. C. Antonucci, J. S. Jackson, S. Biggs, Intergenerational relations: Theory, research, and policy. J. Soc. Issues 63, 679-693 (2007).

39. T. M. Cooney, P. A. Dykstra, "Theories and their empirical support in the study of intergenerational family relationships in adulthood" in Handbook of Family Theories: A Content-Based Approach, M. A. Fine, F. D. Fincham, Eds. (Routledge/Taylor and Francis, New York, 2013), pp. 356-378.

40. M. Silverstein, V. L. Bengtson, Do close parent-child relations reduce the mortality risk of older parents? J. Health Soc. Behav. 32, 382-395 (1991)

41. D. H. Mansson, The joy of grandparenting: A qualitative analysis of grandparents. J. Intergenerational Relationships 14, 135-145 (2016).

42. S. Kumar, Corona virus outbreak: Keep physical distancing, not social distancing. https://papers.ssrn.com/sol3/papers.cfm?abstract_id=3568435. Accessed 28 March 2020.

43. D. Carr, Mental health of older widows and widowers: Which coping strategies are most protective? Aging Ment. Health 24, 291-299 (2020).

44. S. K. Brooks et al., The psychological impact of quarantine and how to reduce it: Rapid review of the evidence. Lancet 395, 912-920 (2020).

45. A. Börsch-Supan, Survey of Health, Ageing and Retirement in Europe (SHARE), release version: 7.1.0. http://share-project.org/home0.html. Accessed 8 June 2020.

46. Italian National Statistical Office (ISTAT), Family and Social Subjects (FSS) survey ("Famiglie, soggetti sociali e ciclo di vita"). https://www.istat.it/it/archivio/236637. Accessed 8 June 2020

47. O. Wahltinez, K. Murphy, M. Brenner, M. Lee, A. Erlinger, Data from "COVID-OpenData: Curating a fine-grained, global-scale COVID-19 data repository." GitHub. https://github.com/open-COVID-19/data\#response. Accessed 8 June 2020.

48. J. M. Aburto et al, Data from "COVerAGE-DB: COVID-19 cases, deaths, and tests by age and sex." GitHub. https://github.com/timriffe/covid_age. Accessed 8 June 2020.

49. Direção-Geral da Saúde, Novo coronavírus COVID-19: Relatório de situação. https:// covid19.min-saude.pt/wp-content/uploads/2020/05/56_DGS_boletim_20200427 NOVO.pdf. Accessed 8 June 2020.

50. Italian Institute of Health, Epidemia COVID-19: Aggiornamento nazionale. https:// www.epicentro.iss.it/coronavirus/bollettino/Bolletino-sorveglianza-integrata-COVID19_28-aprile-2020_appendix.pdf. Accessed 8 June 2020.

51. C. Bohk-Ewald, C. Dudel, M. Myrskylä, A demographic scaling model for estimating the total number of COVID-19 infections. arXiv:https://arxiv.org/abs/2004.12836 (29 April 2020).

52. Presidenza del Consiglio dei Ministri Dipartmento della Protzione Civile, Dati COVID-19 Italia." GitHub. https://github.com/pcm-dpc/COVID-19. Accessed 8 July 2020. 